\title{
Diferentes tempos de eletroestimulação neuromuscular (eenm) de média frequência (kotz) em cães
}

\author{
Different times of neuromuscular electrical stimulation medium frequency (kotz) in dogs
}

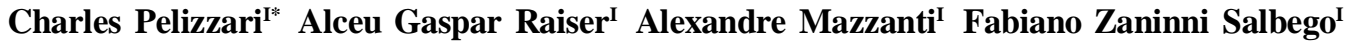 Rafael Festugatto ${ }^{\mathrm{I}}$ Diego Vilibaldo Beckmann ${ }^{\mathrm{I}}$ Marina Gabriela Monteiro Carvalho Mori da Cunha ${ }^{\mathrm{I}}$ Rosmarini Passos dos Santos ${ }^{\mathrm{I}}$ Gabriele Maria Callegaro Serafini ${ }^{\mathrm{I}}$ Jenifer de Santana Marques ${ }^{\mathrm{II}}$ Raquel Baumhardt ${ }^{\mathrm{II}}$}

RESUMO

O objetivo desta pesquisa foi empregar a estimulação elétrica neuromuscular (EENM) de média frequência no músculo quadríceps femoral de cães com atrofia muscular induzida, avaliar o ganho de massa muscular $e$ comparar a EENM sob diferentes tempos de tratamento. Foram utilizados oito cães, pesando entre 15 e $25 \mathrm{~kg}$ e distribuídos aleatoriamente em dois grupos denominados de GI (30minutos) e GII (60minutos). Para a indução da atrofia muscular, a articulação do joelho direito foi imobilizada por 30 dias por transfixação percutânea tipo II. Após a retirada do aparelho de imobilização, foi realizada a EENM nos cães dos grupos GI e GII três vezes por semana, com intervalo mínimo de 48 horas entre cada sessão, pelo período de 60 dias. Foram mensuradas a perimetria da coxa, goniometria dos joelhos, atividade da enzima creatina-quinase $(C K)$ e morfometria das fibras musculares do vasto lateral em cortes transversais colhido mediante a biópsia muscular. Não houve diferença quanto aos valores da perimetria da coxa e atividade da enzima $C K$. A goniometria revelou significância $(P<0,05)$ nos grupos $G I$ e GII entre os tempos zero e 30 minutos. Os grupos GI e GII apresentaram aumento significativo $(P<0,05)$ da área de secção quando comparados com o dia zero e noventa. Podese concluir que a EENM de média frequência ocasiona hipertrofia do músculo vasto lateral em cães após atrofia muscular induzida. A EENM com duração de 60minutos (GII) promove um maior ganho de massa muscular em relação ao GI.

Palavras-chave: cão, imobilização, biopsia, EENM.

\begin{abstract}
The aim of this study was to use medium frequency Neuromuscular Electrical Stimulation (NMES) in femoral quadriceps muscle of dogs with induced muscular atrophy to evaluate the occurrence of mass gain in these muscles and to compare NMES in different periods of treatment. Eight dogs, weighing between 15 and $25 \mathrm{~kg}$, were randomly placed in two groups: GI (NMES for 30min), GII, (NMES for 60min). For the muscular atrophy induction, the right knee was immobilized for 30 days by the percutaneous transfixation type II method. NMES was carried out in the dogs of which groups, three times a week, in between $48 \mathrm{~h}$ each session, in a period of 60 days. The parameters measured were: thigh perimetry, knee goniometry, creatine kinase $(C K)$ enzyme activity and morphometry of the muscular fibers in transversal cuts of the vastus lateralis muscle, collected through a muscular biopsy. There was no significant difference regarding the values of thigh perimetry and $C K$ enzyme activity. The goniometry presented a significant increase $(P<0.05)$ in the groups GI and GII at 30 days from the surgical procedure for immobilization when compared with time zero. In the vastus lateralis fibers morphometry, a significant increase $(P<0.05)$ was observed in the transversal area of the treated groups GI e GII at 90 days from the surgical procedure for immobilization when compared with time zero. Thus, it can be concluded that NMES of medium frequency causes hypertrophy of the vastus lateralis muscle in dogs after induced muscular atrophy. NMES for 60min (GII) presents a greater muscular gain related to the GI.
\end{abstract}

Key words: dog, immobilization, biopsy, NMES.

\footnotetext{
'Programa de Pós-graduação em Medicina Veterinária, Centro de Ciências Rurais (CCR), Universidade Federal de Santa Maria (UFSM), 97105-900, Santa Maria, RS, Brasil. E-mail: charlespelizzari@ yahoo.com.br . *Autor para correspondência.

"Universidade de Santo Amaro (UNISA), Santo Amaro, SP, Brasil.

"I'Universidade Luterana do Brasil (ULBRA), Canoas, RS, Brasil
} 


\section{INTRODUÇÃO}

A atrofia muscular pode ser o resultado do desuso prolongado de um membro em decorrência de afecções ortopédicas ou neurológicas (SALTER et al., 2003; MILLIS, 2004) e após procedimentos cirúrgicos que necessitam de imobilização articular prolongada (MORRISSEY et al., 1985; APPELL, 1986), sendo observada tanto em animais (MILLIS, 2004; MAZZANTI, 2002) como em seres humanos (GOULD et al., 1983; GIBSON et al., 1988). Entre as sequelas encontradas, pode-se citar a diminuição da força muscular, a instabilidade e a rigidez articular (GOSSMAN et al., 1986) e a diminuição da síntese das proteínas musculares (GIBSON et al., 1988).

Entre quatro e seis dias após a imobilização de um membro, ocorre a perda de proteínas musculares, porém a quantidade de mioglobina permanece inalterada (BOOTH, 1977). Após o sétimo dia, há perda de tecido conjuntivo e também de fibras musculares por área de secção do músculo, promovendo alterações como atrofia muscular e redução da atividade contrátil. Essas alterações ocorrem também durante longos períodos de inatividade muscular (WILLIAMS et al., 1988). Ocorre ainda substituição de miofibras atróficas por células de gordura (McGAVIN, 1998).

A estimulação elétrica neuromuscular (EENM) é utilizada há mais de 40 anos para prevenir a atrofia muscular por desuso, aumentar os efeitos de um programa de exercícios após traumatismo e restituir a função em pacientes com distúrbios neuromusculares (OGINO et al., 2002). É uma forma de estímulo capaz de induzir o músculo estriado esquelético a alterações como melhora da função(WILLIAMS \& STREET, 1976), aumento da capacidade de gerar força muscular e hipertrofia (CURRIER et al., 1979; PELIZZARI et al., 2008), além de ser utilizada na estimulação para controle da dor (ROSEMBERG et al., 1978).

Os parâmetros de aplicação da EENM utilizados, na maioria das vezes, em animais são extrapolação de bibliografias consultadas da fisioterapia humana, sem estudos comprobatórios em animais, principalmente o cão, gerando dúvidas em relação à aplicação, número de sessões e tempo de tratamento. O objetivo desta pesquisa foi avaliar a ocorrência de ganho de massa muscular utilizando a estimulação elétrica neuromuscular de média frequência (corrente de Kotz) no músculo quadríceps femoral de cães com atrofia muscular induzida e comparar a EENM sob diferentes tempos de tratamento.

\section{MATERIAL E MÉTODOS}

Foram utilizados oito cães, sem raça definida, pesando entre 15 e $25 \mathrm{~kg}$, obtidos no Biotério Central da Instituição de origem. Os animais foram alojados em canis individuais, por um período mínimo de 15 dias para adaptação ao local, onde receberam alimentação duas vezes ao dia e água à vontade. Foi administrado anti-helmintico (pamoato de pirantel/ praziquantel) na dosagem de $25 \mathrm{mg} \mathrm{kg}^{-1}$ de peso corporal.

Os animais foram submetidos a exame clínico e ortopédico. Foram anestesiados com tiopental sódico $\left(12,5 \mathrm{mg} \mathrm{kg}^{-1}\right)$ para estudo radiográfico simples da articulação coxal e do joelho em incidência crâniocaudal em busca de alterações articulares. Os animais que não apresentaram alterações foram distribuídos ao acaso em dois grupos de igual número, denominados de GI com aplicação de EENM por 30 minutos e GII com aplicação de EENM por 60 minutos.

Os procedimentos cirúrgicos empregados nestes animais foram biópsia do músculo vasto lateral, para avaliação das fibras musculares e imobilização rígida temporária da articulação do joelho. As biopsias foram realizadas em três tempos: antes da imobilização, no momento de sua retirada e 90 dias após a primeira.

Para a imobilização articular, cada animal foi submetido à tricotomia da coxa direita e pré-medicado com sulfato de morfina ( $1 \mathrm{mg} \mathrm{kg}^{-1}$ ) associado ao maleato de acepromazina $\left(0,05 \mathrm{mg} \mathrm{kg}^{-1}\right)$. A anestesia foi induzida com propofol $\left(4,0 \mathrm{mg} \mathrm{kg}^{-1}\right)$ e mantida com halotano vaporizado em oxigênio a $100 \%$. Após a antissepsia do campo operatório, realizada com álcool-iodo-álcool, foi administrada ampicilina sódica $\left(30 \mathrm{mg} \mathrm{kg}^{-1}\right), 30$ minutos antes do início da cirurgia, sendo efetuada a fixação externa percutânea biplanar ou tipo II, conforme descrito por ARON (1996). A articulação foi mantida em angulação de $90^{\circ}$ com o auxílio de um goniômetro. Como barra de conexão entre os pinos, foi utilizada resina acrílica autopolimerizável. Os animais receberam como terapia anti-inflamatória e analgésica cetoprofeno $10 \%\left(2 \mathrm{mg} \mathrm{kg}^{-1}\right)$, por via subcutânea, durante três dias e cloridrato de tramadol $\left(2 \mathrm{mg} \mathrm{kg}^{-1}\right)$, por via intramuscular, a cada seis horas durante $24 \mathrm{~h}$. As áreas de inserções dos pinos, na pele, foram higienizadas com solução salina isotônica, protegidas por gaze embebida em solução de nitrofurazona e o aparelho de imobilização diariamente recoberto com atadura até a sua remoção.

No mesmo instante da implantação dos pinos, foi realizada a primeira biopsia por incisão da pele e da fáscia muscular e introdução de um trépano dermatológico no músculo vasto lateral do membro pélvico direito. O fragmento da biopsia, de 
aproximadamente $7 \times 3 \mathrm{~mm}$, foi retirado mediante movimentos de rotação e alavanca, fixado em formol tamponado a $10 \%$ por um período mínimo de $48 \mathrm{~h}$. A ferida da pele, em consequência da biópsia muscular, após sutura com fio mononáilon 4-0, foi higienizada com solução salina isotônica e protegida por esparadrapo hipoalergênico.

Os animais permaneceram com o aparelho de fixação esquelética por 30 dias, quando foi realizado novo procedimento cirúrgico que constou da segunda biópsia e retirada do aparelho. Após 48 horas da segunda biópsia, iniciou-se a EENM. Para isso, foi feita a tricotomia da coxa direita e remoção da oleosidade com álcool para a redução da resistência da passagem de corrente elétrica. Dois eletrodos de canais diferentes foram colocados sobre os pontos motores (THOMSON \& BOWEN, 1971) dos músculos vasto medial e vasto lateral e os restantes situados sobre os mesmos músculos, o mais distante possível entre eles para fechamento de corrente numa disposição diagonal. Foi aplicado gel condutor apropriado (Mercur ${ }^{\circledR a}$ ) de aproximadamente três milímetros de espessura sob os eletrodos, posicionados conforme a técnica quadripolar (KITCHEN, 2003) e fixados com fita elástica.

Os parâmetros da corrente emitida pelo aparelho de EENM (Neurodyn $\mathrm{II}^{\mathrm{b}}$ ) foram frequência de $2500 \mathrm{~Hz}$, largura do pulso de 50\%, modo sincronizado, com ciclos de estimulação de 12 segundos seguidos por 25 segundos de descanso (relação on:off de 1:2). A rampa de subida (rise) foi de três segundos e descida (decay) do pulso de três segundos. A intensidade de corrente foi controlada de acordo com o desconforto do animal ao estímulo (vocalização, inquietude, retirada do membro estimulado). Os músculos estimulados foram as quatro cabeças do músculo quadríceps femoral, ou seja, vasto lateral, vasto medial, vasto intermédio e reto femoral.

Os cães do GI receberam aplicação de EENM de Média Frequência (corrente de Kotz ou Russa), três vezes na semana, com intervalo de $48 \mathrm{~h}$ entre as sessões com duração de 30 minutos, até o $60^{\circ}$ dia após a remoção do aparelho de fixação externa. Os cães do GII receberam o mesmo tratamento por 60 minutos.

A terceira biópsia muscular foi realizada aos 90 dias após a primeira. Os fragmentos da biópsia muscular do vasto lateral foram corados por Hematoxilina e Eosina, efetuando-se estudos morfométricos em corte transversal. Cada lâmina histológica foi fotografada com câmera digital acoplada ao microscópio com objetiva de 20X. A imagem obtida foi dividida em vinte partes iguais e mensurou-se a área de secção da fibra muscular, que se localizava no centro de cada divisão através do programa Alfa Easer $F C^{\circledR}$.
Outras avaliações complementares constaram de medida da perimetria da coxa, goniometria da articulação do joelho e atividade da enzima creatinaquinase (CK). Para a medida da perimetria, realizou-se a tricotomia da coxa em ambos os membrose, com uma fita maleável $(\mathrm{em} \mathrm{cm})$, foram marcados três pontos equidistantes entre o trocânter maior e o côndilo lateral do fêmur e nesses pontos foi aferida a perimetria. Logo após, utilizou-se goniômetro universal para mensurar as angulações em flexão e extensão total do joelho, obtendo-se o arco de movimento. Esses procedimentos foram realizados nos dias 0 (pré), 30 e 90 dias após a primeira medida e os valores foram anotados em protocolos específicos. Para a avaliação da atividade da enzima CK, foi utilizado o teste CK-NAC. Coletouse $5 \mathrm{ml}$ de sangue nos dias zero, 30, 45, 60 e 90 após a primeira coleta. Com exceção do dia zero, as coletas foram distribuídas em três tempos: antes (T0), duas (T1) e seis (T2) horas após EENM.

Para o cálculo estatístico, utilizou-se análise de variância (ANOVA) de uma via, seguida de teste de comparações múltiplas de Duncan. Todos os resultados foram indicados pela média \pm do Erro Padrão da Média (EPM).

\section{RESULTADOS E DISCUSSÃO}

Os valores da perimetria da coxa sofreram variações (Figura 1), no entanto, não apresentaram diferença entre os grupos nos diferentes tempos de avaliação, corroborando SOUZA et al. (2007), demonstrando que este tipo de mensuração é relativa, já que a EENM foi realizada apenas no músculo quadríceps femoral e não em todo grupamento muscular da coxa e diferindo de JOHNSON et al. (1997), que testaram a estimulação elétrica em cães após artroplastia do joelho e encontraram diferença significativa na mensuração da circunferência da coxa entre os cães tratados e não tratados. Na medida da goniometria, houve diferença estatística $(\mathrm{P}<0,05)$ entre os grupos no membro imobilizado (direito) no $30^{\circ}$ dia de pósoperatório (Figura 1), que se deve aos diferentes graus de rigidez articular encontrados nos animais dos grupos, pois essa medida foi realizada logo após a retirada da imobilização.

Quanto à análise da atividade da enzima creatina quinase (CK), não houve diferença estatística entre os animais dos grupos I e II em relação ao tempo de coleta. A escolha da creatina quinase (CK) foi baseada no trabalho de BURR et al. (1997), os quais descreveram que a enzima CK é de maior confiança para avaliar injúria muscular, e de BIGARD (2001), que citou o aumento da atividade desta enzima quando há 


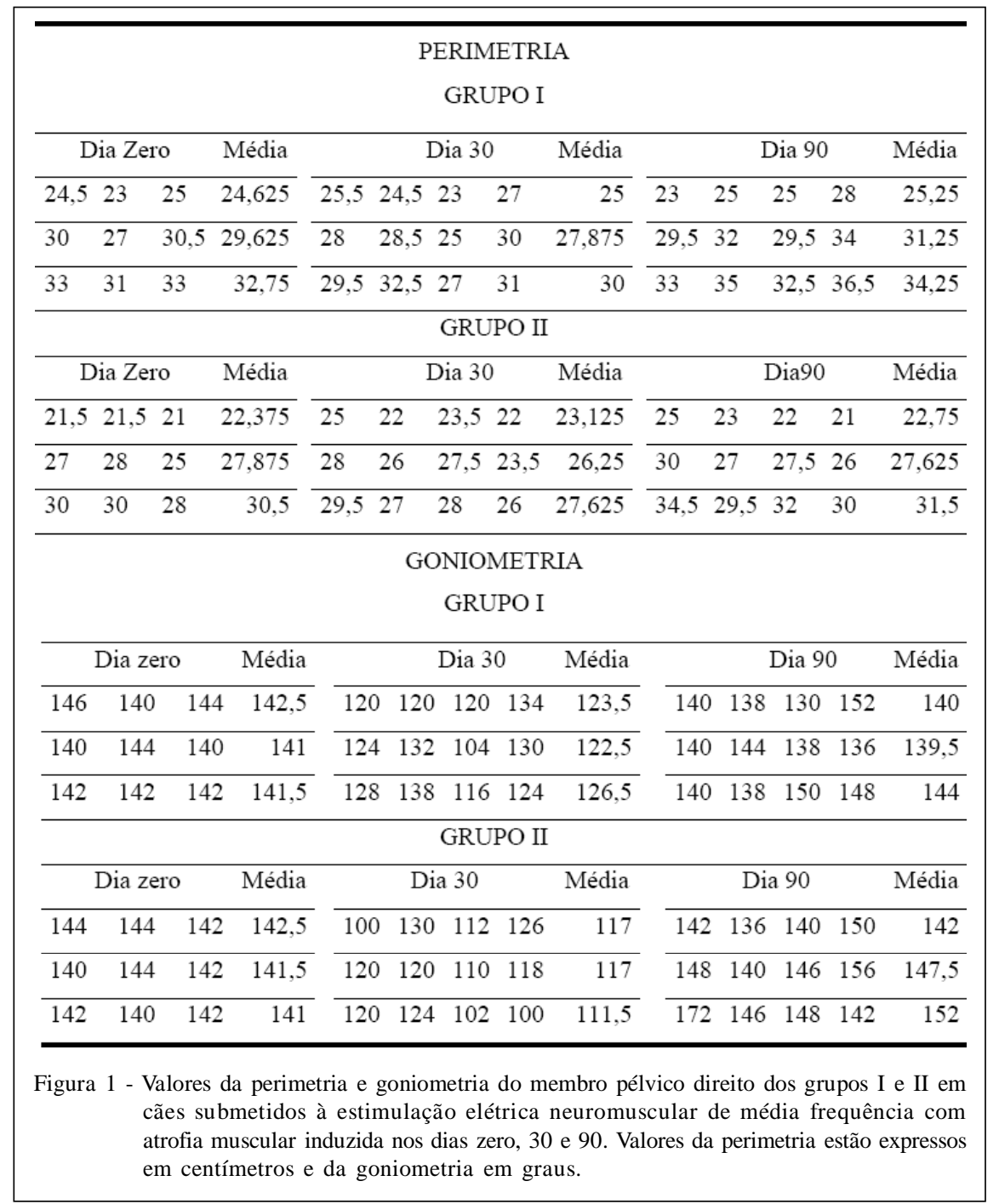

fadiga muscular. Evidenciou-se variação da atividade da enzima CK em relação aos tempos de coleta, porém dentro dos valores considerados fisiológicos. POSO et al. (1983) revelaram um aumento da atividade da CK após exercícios acentuados, enquanto que, em trabalhos mais leves, não houve aumentos significativos, sugerindo que a intensidade pode ser um fator importante para o aumento da atividade da enzima (SHELLE et al., 1985). Geralmente, quando ocorrem lesões musculares por intensidade de exercícios físicos, outros sinais clínicos são observados como dor à palpação (miosite) e às vezes claudicação (PELIZZARI et al., 2008). Nesta pesquisa, não foi encontrada nenhuma manifestação clínica de algias musculares durante o tratamento, coincidindo com os valores da CK sem significância estatística. Entendemos que para chegar ao consenso de dano muscular deve- se associar o aumento da CK com atividade física acentuada. A relação on time/off time de 1:2 empregada neste experimento pode justificar estes achados, coincidindo com SOUZA (2006), que empregou a EENM no músculo quadríceps femoral de cães com atrofia muscular induzida e não encontrou aumento significativo de CK.

Nos animais do grupo I, não houve diferença significativa entre os dias zero e 30 , sendo notada uma discreta diminuição da massa muscular causada pelo desuso do membro. Entre os dias zero e 90 , houve aumento significativo $(\mathrm{P}<0,05)$ no ganho de massa muscular ultrapassando o valor médio da área das fibras musculares no tempo zero, sugerindo a influência da EENM sobre o músculo vasto lateral (Figura 2A). No grupo II, houve diferença $(\mathrm{P}<0,05)$ entre os dias zero, 30 e 90 dias, em relação ao ganho de massa muscular. A diferença encontrada nos dias zero e 30 


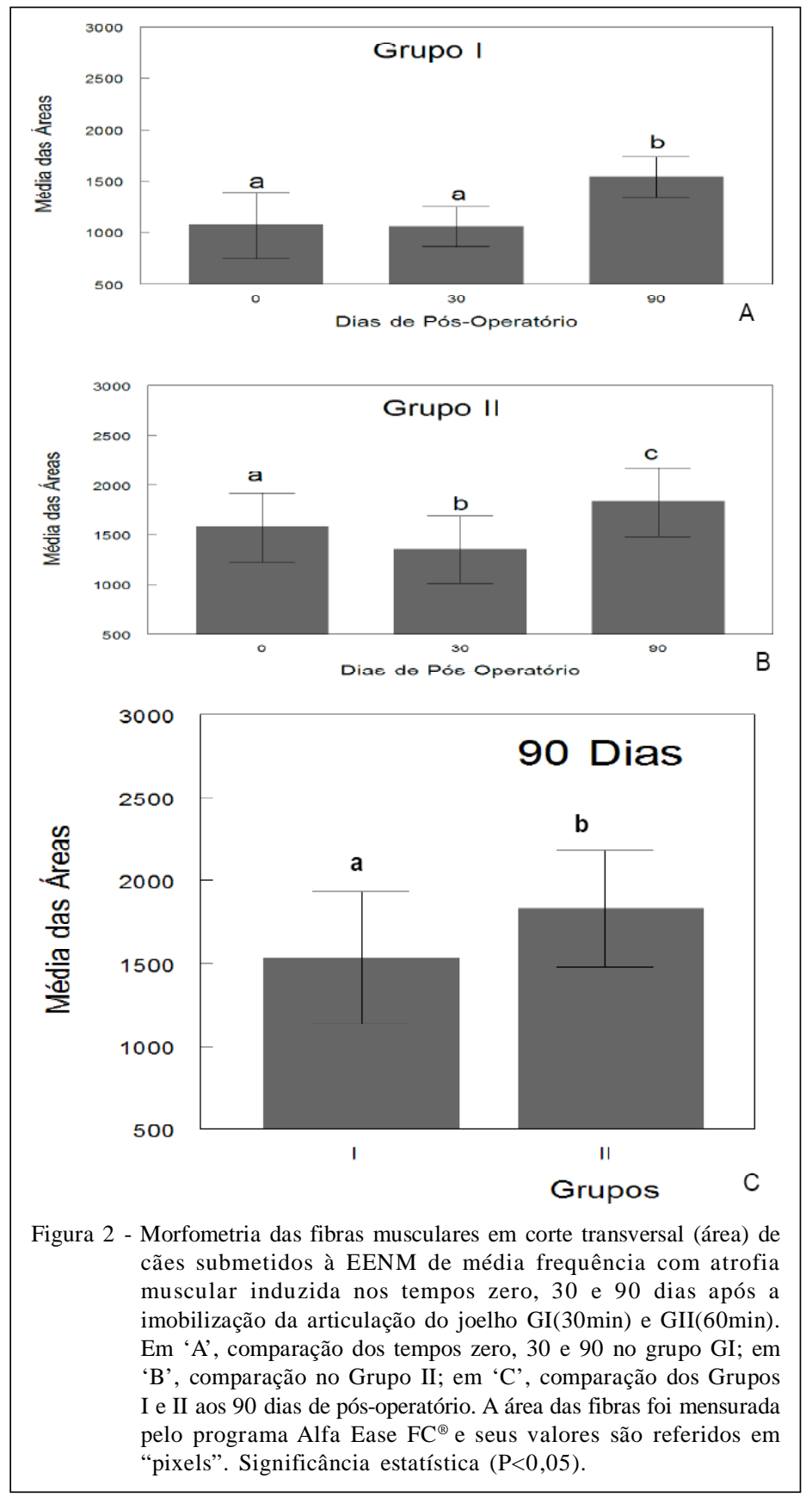

pode ser atribuída à atrofia muscular causada pelo membro pélvico em desuso e aquela observada entre os dias zero e 90 dias, pela influência da EENM, ocasionando um ganho significativo $(\mathrm{P}<0,05)$ de massa muscular (Figura 2B), o que também foi observado por PELIZZARI et al. (2008) ao empregarem a estimulação elétrica funcional de baixa frequência.

Evidenciou-se a influência da EENM de média frequência sobre o ganho de massa muscular, analisando a média das áreas das fibras musculares dos animais do grupo I e do grupo II entre o tempo zero e 90 dias de PO, pois tiveram valores significativos $(\mathrm{P}<0,05)$ o que caracteriza ganho de massa muscular. Quando avaliados aos 90 dias, foi observado diferença $(\mathrm{P}<0,05)$ do grupo II em relação ao grupo I (Figura 2C). O tempo de duração de cada sessão de EENM (60 minutos) nos animais do grupo II provavelmente tenha promovido a estimulação elétrica das fibras musculares por mais tempo, ocasionando maior ganho de massa muscular em relação ao outro grupo. 


\section{CONCLUSÃO}

A estimulação elétrica neuromuscular (EENM) de média frequência ocasiona ganho de massa muscular em cães com atrofia muscular induzida.

A duração de 60 minutos de EENM promove maior ganho de massa muscular em relação ao tempo de 30 minutos.

\section{COMITÊ DE ÉTICA E BIOSSEGURANÇA}

Este trabalho seguiu as normas de experimentação segundo o Comitê de Ética Experimental para o uso de animais da Universidade Federal de Santa Maria e foi aprovado constando no Processo Administrativo n. 23081.009802/2006-21.

\section{AGRADECIMENTO}

Ao Conselho Nacional de Desenvolvimento Científico e Tecnológico (CNPq), pelo financiamento da pesquisa vinculada ao processo 300885/2008-3.

\section{FONTES DE AQUISIÇÃO}

a - Gel para US -Mercur S/A, Santa Cruz do Sul, RS.

b - Neurodin II- Ibramed Indústria Brasileira de Equipamentos Médicos, Amparo, SP.

\section{REFERÊNCIAS}

APPELL, H.J. Skeletal muscle atrophy during immobilization. Internal Journal Sports Medicine, v.7, n.1, p.6-12, 1986.

ARON, D.N. Tendões. In: BOJRAB, M.J. Técnicas atuais em cirurgia de pequenos animais. 3.ed. São Paulo: Roca, 1996. Cap.40, p.516-527.

BIGARD, A.X. Lesions musculaires induites par léxercice et surentraîntemente. Science \& Sports, v.16, p. 204-215, 2001.

BOOTH, F.W. Time course of molecular atrophy during immobilization od hinlimbs in rats. Journal of Aplied Physiology, v.43, n.5, p.656-661, 1977.

BURR, J.R. et al. FERUM biochemical values in sled dogd befote and alter competing in long-distance races. Journal American Veterinary Medical Association, v.211, n.2, p.175-179, 1997

CARDINET III, G.H. Skeletal muscle function. In: KANECO, J.J. et al. Clinical biochemistry of domestic animals. 5.ed. California: Academic, 1997. Cap.16, p.407-440, 1997.

CURRIER, D.P. et al. Electrical stimulation in exercise of the quadriceps femoris muscle. Physical Therapy, v.59, n.12, p.1508-1512, 1979.

GIBSON, J.N.A. et al. Prevention of difuse muscle atrophy by means of electrical stimulation: maintenance of protein synthesis. Lancet, v.2, n.8614, p.767-770, 1988.

GOSSMAN, M.R. et al. Length and circumference measurements in on joint and multi-joint muscle in rabbits after immobilization. Physical Therapy, v.66, n.4, p.516$520,1986$.

GOULD, N. et al. Transcutaneous muscle stimulation to retard disuse atrophy after open meniscectomy. Transcutaneous Muscle Stimulation, v.9, n.178, p.190-197, 1983.

JOHNSON, J.M. et al. Rehabilitation of dogs with surgically treated cranial cruciate ligament-deficient stifles by use of electrical stimulation of muscles. American Journal Veterinary Research, v.58, n.12, p.1473-1478, 1997.

KITCHEN, S. Eletroterapia. Prática baseada em evidência. 11.ed. São Paulo: Manole, 2003. 348p.

MAZZANTI, A. Homoimplante ortotópico conservado, associado à terapia "soft laser" na reparação tenopatelar em cão. 2002. 80f. Tese (Doutorado em Cirurgia) Universidade Federal de Santa Maria, Santa Maria, RS.

McGAVIN, R. Músculos. In: CARLTON, W.W.; McGAVIN, R. Patologia veterinária especial de Thompson. 2.ed. Porto Alegre: ArtMed, 1998. p.426.

MILLIS, D.L. Responses of musculoskeletal tissues to disuse and remobilization. In: MILLIS, D.L. et al. Canine rehabilitation \& physical therapy. Missouri: Elsevier, 2004. Cap. 7, p.113-159.

MORRISSEY, M.C. et al. The effects of electrical stimulation on the quadriceps during postoperative knee immobilization. American Journal of Sports and Medicine, v.13, n.1, p.40$45,1985$.

OGINO, M. et al. MRI quantification of muscle activity after volitional exercise and neuromuscular electrical stimulation. American Journal of Physical and Medicine Rehabilitation, v.81, n.6, p.446-451, 2002.

PELIZZARI C. et al. Estimulação elétrica neuromuscular de baixa frequência em cães com atrofia muscular induzida. Arquivo Brasileiro Medicina Veterinária e Zootecnia, v.60, n.1, p.76-82, 2008. Dispoível em: <http://www.scielo.br/

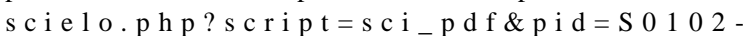
$09352008000100012 \& \operatorname{lng}=p t \& n r m=i s o \& t \operatorname{lng}=p t>$. Acesso em: 08 jul. 2008. doi: 10.1590/S0102-09352008000100012.

POSO, A.R. et al. The effect of exercise on blood parameters in standardbred and Finnish-bred horses. Acta Veterinary Scandinavica, v.24, n.2, p.170-184, 1983.

ROSEMBERG, M. et al. Trans-cutaneous electrical nerve stimulation for relief of postoperative pain. Pain, v.5p.129. 133,1978 .

SALTER, A.C. et al. Prevention of muscle atrophy bylowfrequency electrical stimulation in rats. Transactions on Neural Systems and Rehabilitation Enginnering, v.11, n.3, p.218-226, 2003

SHELLE, J. E. et al. Blood parameters as a result of conditioning horses through short strenuous exercise bouts. In: EQUINE NUTRITIONAL PHYSIOLOGY SIMPOSIUM, 9., 1985., East Lansing. Proceedings... East Lansing: The Equine Nutrition and Physiology and Michigan State University, 1985. p.206. 
SOUZA, S.F. Estimulação elétrica neuromuscular em cães submetidos a imobilização rígida temporária da articulação femoro-tibio-patelar. 2006. 84f. Dissertação (Mestrado em Medicina Veterinária) - Universidade Federal de Santa Maria, RS.

SOUZA, S.F. et al. Estimulação elétrica neuromuscular em cães submetidos á imobilização rígida temporária da articulação femoro-tibio-patelar. Ciência Rural, v.37, n.1, p.165-170, 2007. Disponível em: <http://www.scielo.br/pdf/cr/v37n1/ a26v37n1.pdf>. Acesso em: 29 jan. 2007. doi: 10.1590/S010384782007000100026 .
THOMSON, F.K.; BOWEN, J.M. Eletrodiagnostic testing: mapping and clinical use of motor points in the dog. Journal of the American Veterinary Medical Association, v.159, n.12, p.1763-1771, 1971.

WILLIAMS, F.A. et al. The importance of stretch and contractile activity in the prevention of connective tissue accumulation in muscle. Journal of Anatomy, v.158, p.109114, 1988.

WILLIAMS, J.P.C.; STREET, M. Sequential faradism in quadriceps rehabilitation. Physiotherapy, v.116, n.1, p.4555, 1976 . 